\title{
Isolated Thoracoschisis: Case Report and Review of Literature
}

\author{
Hamed Mahmoud Seleim ${ }^{1} \quad$ Mahmoud M.A. ElFiky ${ }^{1} \quad$ Ahmed E. Fares $^{1} \quad$ Mohamed M. Elbarbary $^{1}$ \\ ${ }^{1}$ Department of Pediatric Surgery, Cairo University, Cairo, Egypt \\ Eur J Pediatr Surg Rep 2015;3:40-42. \\ Address for correspondence Hamed Mahmoud Seleim, FEBPS, Cairo \\ University Specialized Pediatric Hospital, Cairo 11632, Egypt \\ (e-mail: hamed_seleim@yahoo.com).
}
Abstract
Keywords
- thoracoschisis
- gastroschisis
- silo
- limb-body wall complex

A full-term male baby presented at day 2 postnatal with Riedel liver lobe, stomach, and much of the bowel herniating through a thoracic wall defect located just above and lateral to the left nipple. Operative conversion into a gastroschisis-like defect with construction of a silo bag was done. On thorough review of literature, it was found that this is only the second male infant reported with isolated thoracoschisis.

\section{Introduction}

Evisceration of abdominal contents through a defect in the thoracic wall is an extremely rare congenital malformation. It may present itself as an isolated anomaly or usually or more commonly be associated with limb and abdominal wall defects representing the limb-body wall complex (LBWC). ${ }^{1-3}$ Early amnion rupture and embryonic maldevelopment are possible issues relating to the pathogenesis of this malformation. ${ }^{4}$

\section{Case Report}

A full-term male baby weighing $2.7 \mathrm{~kg}$ was delivered by cesarean section at 39 weeks of gestation to a 29-year-old woman who had three earlier pregnancies and three live births by cesarean sections. No prenatal ultrasonography was done. The baby presented at day two postnatal from a remote village in Upper Egypt, where no tertiary care neonatal center is available. The infant's condition was mishandled and the baby was wrapped in nonsterile cotton clothes. The baby was admitted at the surgical NICU at Cairo University Specialized Pediatric Hospital two days after delivery.

Examination revealed poor general conditions with absent suckling and Moro reflexes, mostly due to lack of any resuscitative measures for an entire day. Much of the abdominal viscera were eviscerated through the left anterior thoracic wall leaving scaphoid abdomen. Both the upper and lower limbs were normal. There were no other apparent phenotypic anomalies. Resuscitation was started after wrap-

received

September 11, 2014 accepted after revision

October 16, 2014

published online

December 3, 2014 ping the eviscerated gut with a sterilized transparent plastic film.

Transthoracic echocardiography showed dextrocardia, mostly due to displacement, and $3 \mathrm{~mm}$ patent ductus arteriosus.

After about 6 hours of resuscitation, operative exploration was taken under general inhalational anesthesia. The chest wall defect was located at the left side of the thoracic cage, just above and lateral to the nipple, in the anterior axillary line. The defect was narrow $(3 \times 2 \mathrm{~cm})$, with evisceration of Riedel lobe of the liver, stomach, and much of the intestine ( - Fig. 1). The eviscerated intestine, though viable, was edematous, matted, and covered by pyogenic membrane.

Extension of the defect revealed an intact left dome of diaphragm. The anterior attachment of the diaphragm into the rib cage was just above the thoracoschisis defect, and from that point, its lateral thoracic attachment was sequentially sloping downward and backward till it reached the 9th rib at the posterior axillary line ( - Fig. 2). There was no loss of ribs, but just widely separated fourth and fifth ribs. It was impossible to reduce the eviscerated guts through the thoracic defect. So, conversion into gastroschisis-like defect was done through extension of the thoracic defect into the upper abdomen with construction of a hand-sewn silo bag to contain the severely matted and thickened bowel (-Fig. 3). Then, the thoracic wall was closed with reapproximation of the separated ribs using 2/0 Vicryl.

Unfortunately, the baby died from profound sepsis two days postoperatively. The preadmission long time of
License terms Stuttgart · New York

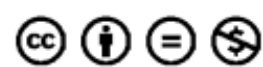




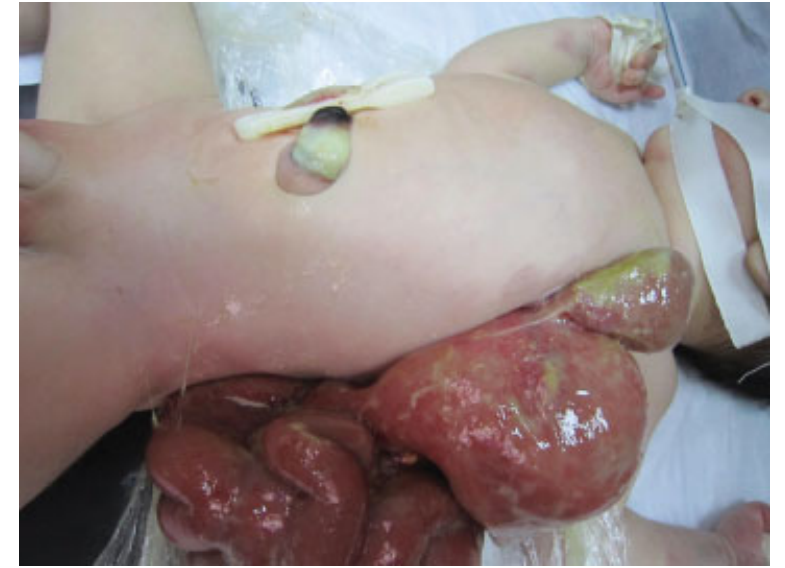

Fig. 1 A photo showing Riedel lobe of liver, part of stomach, and small bowel herniating through a chest wall defect superior-lateral to the left nipple.

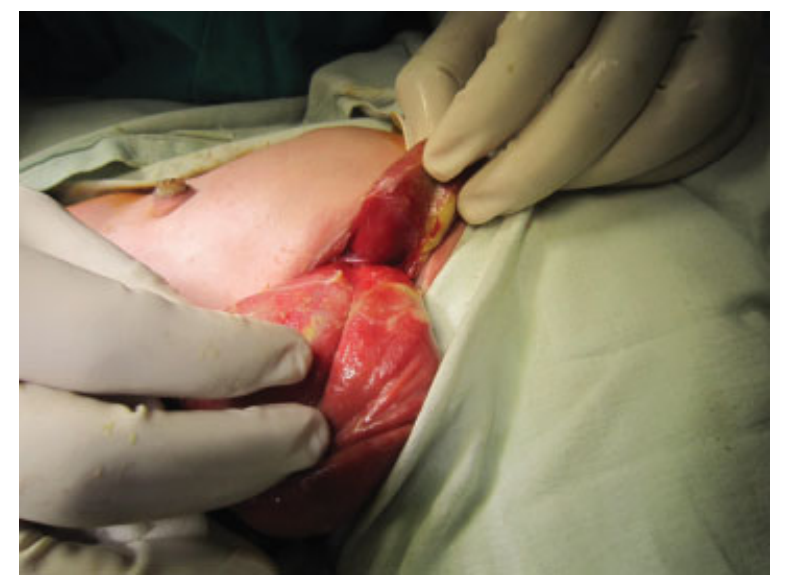

Fig. 2 Separation of Riedel lobe of liver from anterior gastric wall.

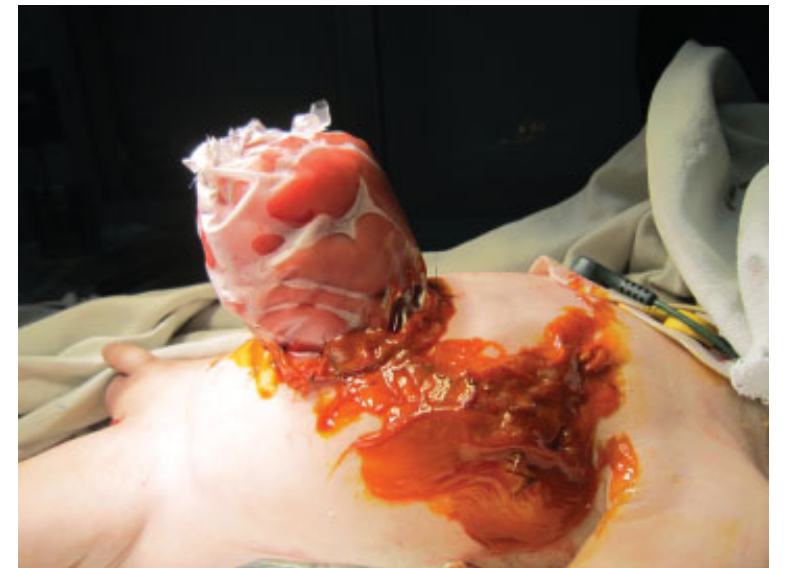

Fig. 3 Conversion into gastroschisis-like defect with construction of hand-sewn silo bag.

negligence, dehydration, and contamination was sufficient to cause such a miserable course.

\section{Discussion}

Thoracoschisis is a very rare congenital malformation where there is herniation of abdominal contents through a lateral rib cage defect. ${ }^{5}$ This anomaly usually presents itself as part of LBWC, where there is associated ipsilateral phocomelia and diaphragmatic defect, or presents as an isolated malformation.

LBWC was originally diagnosed when there are two of the following three malformations combined, as proposed by Van Allen: (1) exencephaly/encephalocele and facial clefts, (2) thoraco- and/or abdominoschisis, and (3) limb defects. ${ }^{3}$

The constellation of reduction anomaly of the upper limb, ipsilateral deficiency of the anterior chest wall, and diaphragmatic hernia may occur during the 5th and 6th week of gestation as an early embryonic maldevelopment. ${ }^{1}$

Various theories have been proposed to explain these malformations. Van Allen postulates that many congenital malformations could develop as a result of early vascular disruption, which leads to structural maldevelopment. This

Table 1 The documented thoracoschisis cases

\begin{tabular}{|c|c|c|c|c|c|}
\hline Author & Anomaly & Gender & Site & Defect diameter & Covering amniotic sac \\
\hline Davies et al ${ }^{1}$ & LBWC & Female & Left & $\leq 4 \mathrm{~cm}$ & Absent \\
\hline Bamforth et al $^{7}$ & LBWC & Female & Left & $\leq 4 \mathrm{~cm}$ & Absent \\
\hline Derbent and Balci ${ }^{8}$ & LBWC & Female & Right & $\leq 4 \mathrm{~cm}$ & Absent \\
\hline Biri et $\mathrm{al}^{2}$ & LBWC & Female & Left & $\leq 4 \mathrm{~cm}$ & Absent \\
\hline Karaman et al $\left.\right|^{5}$ & Isolated & Male & Left & $\leq 4 \mathrm{~cm}$ & Absent \\
\hline Bhattacharyya et al ${ }^{4}$ & LBWC & Female & Right & $>4 \mathrm{~cm}$ & Present \\
\hline Present case & Isolated & Male & Left & $\leq 4 \mathrm{~cm}$ & Absent \\
\hline Total $(n)$ & $\begin{array}{l}\text { Isolated }=2 \\
\text { LBWC }=5\end{array}$ & $\begin{array}{l}\text { Male }=2 \\
\text { Female }=5\end{array}$ & $\begin{array}{l}\text { Right }=2 \\
\text { Left }=5\end{array}$ & $\begin{array}{l}\leq 4 \mathrm{~cm}=6 \\
>4 \mathrm{~cm}=1\end{array}$ & $\begin{array}{l}\text { Absent }=6 \\
\text { Present }=1\end{array}$ \\
\hline
\end{tabular}

Abbreviation: LBWC, limb-body wall complex. 
theory is considered as a plausible explanation for the occurrence of isolated thoracoschisis.

Riedel lobe of the liver is a tongue-like projection-rather than being a true hepatic lobe-which is attached to the liver surface, mostly at segment VI through a small pedicle, which makes it vulnerable to torsion. It usually occurs as a result of inflammation or attachment to other tissue. ${ }^{6}$

After thorough review of literature, we found six previously reported cases of thoracoschisis (listed in - Table 1 ). The present case is the second as a male infant with isolated thoracoschisis malformation. Karaman et al reported the first male baby with isolated thoracoschisis, where the Riedel lobe and a small part of the transverse colon were herniated through $2 \times 2 \mathrm{~cm}$ defect at the left 8 th intercostal space. The herniated contents were simply reduced into the abdomen. The two cases reported by Davies (1977) ${ }^{1}$ and Bamforth $(1992)^{7}$ were also treated by simple reduction as the small bowel was not herniated. Three other reported cases with this anomaly had died at birth. In the present case, the defect was $3 \times 2 \mathrm{~cm}$ located at the 4 th intercostals space, with Riedel lobe, stomach, and much of the bowel were herniated and covered with fibrinous exudates, necessitating conversion into a gastroschisis/laparoschisis-like defect with a silo bag for safe closure.

\section{Conflict of Interest}

None.

\section{References}

1 Davies, M. R. Q., H. Rode, and S. Cywes. "Thoracoschisis" associated with an ipsilateral distal phocomelia and an anterolateral diaphragmatic hernia-A case report. J Pediatr Surg 1977;12(5):755-757

2 Biri A, Korucuoğlu U, Turp A, Karaoğuz M, Himmetoğlu O, Balci S. A new syndrome with prenatally diagnosed thoracoschisis, hiatal hernia and extremities' agenesis: case report. Genet Couns 2006; 17(2):161-165

3 Van Allen MI, Curry C, Gallagher L. Limb body wall complex: I. Pathogenesis. Am J Med Genet 1987;28(3):529-548

4 Bhattacharyya NC, Gogoi M, Deuri PK. Thoracoschisis with limb agenesis. J Indian Assoc Pediatr Surg 2012;17(2):78-79

5 Karaman I, Karaman A, Erdoğan D, Cavuşoğlu YH, Ozgüner IF. The first male with thoracoschisis: case report and review of the literature. J Pediatr Surg 2011;46(11):2181-2183

6 Kudo M. Riedel's lobe of the liver and its clinical implication. Intern Med 2000;39(2):87-88

7 Bamforth JS, Fabian C, Machin G, Honore L. Poland anomaly with a limb body wall disruption defect: case report and review. Am J Med Genet 1992;43(5):780-784

8 Derbent M, Balci S. Thoracoschisis associated with diaphragmatic hernia in a 31-week-old stillbirth. Turk J Pediatr 2001;43(3): 269-271 